\title{
Ventricular septal defect repair after pulmonary artery banding
}

\author{
Eric N. Coleman, John M. Reid, Robert S. Barclay, and John G. Stevenson \\ From the University Department of Child Health and Department of Cardiology, \\ Royal Hospital for Sick Children, Glasgow, and the Cardio-Thoracic Unit, \\ Mearnskirk Hospital, Glasgow
}

Fifteen children with ventricular septal defects and pulmonary hypertension were operated upon for repair of the septum and reconstruction of the main pulmonary artery three to five years after pulmonary artery banding; one septal defect had closed spontaneously. Thirteen had suffered from congestive cardiac failure before banding, and in Io the palliative operation had been performed in the first year of life. Of the 4 deaths which followed the second operation, $I$ was related to pulmonary arterial obstructive disease. One 8-year-old child with pulmonary vascular disease was subjected to pulmonary artery banding and subsequently survived a complete repair. Results of repair operations did not appear to reflect closely the level of pulmonary vascular resistance measured before the banding operation. Before the second operation the volume of blood passing through the septal defect (relative to systemic blood flow) had on average decreased to 19 per cent of its level before pulmonary artery banding. An estimate has been made of the extent to which the long-term prognosis for infants with ventricular septal defects and congestive cardiac failure has been improved by the introduction of the operation for pulmonary artery banding.

In infants with intractable congestive cardiac failure due to large ventricular septal defects accompanied by pulmonary hypertension, banding of the main pulmonary artery is a relatively safe and reliable palliative procedure (Dammann et al., 196r). The object is to create a pulmonary stenosis whereby the excessive blood flow through the lungs is diminished, pulmonary congestion relieved, further damage to the pulmonary vasculature prevented, and the systemic blood flow improved. Primary repair of ventricular septal defects in the first year of life by the conventional technique has such a high mortality that the palliative banding operation is preferred as a preliminary measure (Oschner et al., 1962; Hallman, Cooley, and Bloodwell, 1966), as it may also be in some older children with severe pulmonary hypertension resulting from pulmonary vascular obstruction (Dammann et al., 1961).

Having previously examined our experience of pulmonary artery banding (Reid et al., 1968), we now describe 15 patients who were later subjected to operation for repair of the defect and reconstruction of the main pulmonary artery.

Received 15 March 1971.

\section{Clinical material}

The I5 patients described were initially investigated at the Royal Hospital for Sick Children, Glasgow, between December 1963 and June 1967, and operated upon in the Cardio-Thoracic Department, Mearnskirk Hospital, Glasgow. There were 7 boys and 8 girls, all but 2 of whom (Cases 3 and 4) had been under 21 months of age at the time of main pulmonary artery banding (Table). The indication for this operation had been congestive cardiac failure, inadequately controlled with drug treatment, in patients with a ventricular septal defect and pulmonary hypertension close to systemic arterial level. Four had, in addition, a persistent ductus arteriosus, and pulmonary artery banding was performed to relieve the pulmonary hypertension remaining after ligation or division of the ductus.

Two older children (aged $2 \frac{7}{12}$ and $8 \frac{6}{12}$ ) had had severe pulmonary hypertension (main pulmonary artery $120 / 60$ and $100 / 50 \mathrm{mmHg}$, respectively) accompanying a ventricular septal defect but uncomplicated by congestive cardiac failure. Repair of these defects was considered hazardous and banding was undertaken with the aim of allowing pulmonary artery disease already present to regress, so permitting a safer repair operation at a later date. Lung biopsy in one (Case 3) revealed proliferation of the internal and external elastic laminae with muscular hypertrophy in the medial coat of the small pulmonary arteries. The other lung biopsy (Case 4) disclosed slight encroach- 
ment on the lumen of pulmonary arterioles from hypertrophy of the media (almost certainly reversible), and to a minor degree from hypertrophy of the intima.

The interval between the two operations was from 3 to 5 years (mean $3 \frac{10}{12}$ years). Cardiac catheterization and angiocardiography were performed before both operations; the last measurement of main pulmonary artery and of right ventricular pressures to be obtained was in theatre after the repair operation had been completed.

For the surgical procedure, standard normothermic cardiopulmonary bypass technique with a disposable oxygenator was used. The ventricular septal defect was repaired by direct suture in 9 and by the use of a Teflon or pericardial patch in 5 patients. The main pulmonary artery constriction was eliminated by suturing transversely a longitudinal incision through the banded segment; in 5 a pericardial patch had to be inserted to give to the artery an adequate lumen. Two patients had each two ventricular septal defects; in all other instances the defect was single.

\section{Results (Table)}

There were 4 deaths (Cases 3, 8, II, and I3) and in each instance the defect was substantial $(20-30 \mathrm{~mm})$. Two were largely attributable to complete heart block produced during repair; in spite of the immediate introduction of continuous electrical pacing, a satisfactory cardiac output could not be maintained and death occurred within 24 hours. Sudden massive haemorrhage was largely responsible for one death on the second postoperative day, while unexplained and inadequately controlled congestive cardiac failure caused the fourth death on the 2Ist postoperative day.
There were no complications in the II survivors. When reviewed 6 to 12 months after their second operation, all were well and active; there had been a regression both in the electrocardiographic evidence of right ventricular hypertrophy and in the radiographic evidence of cardiac enlargement.

The systolic pressure gradient which had been created in the main pulmonary artery by the banding operation was largely eliminated by the second operation in 8 of the II for whom adequate figures were available. The largest persisting systolic gradient indicating some residual stenosis was $25 \mathrm{mmHg}$. Pulmonary hypertension in excess of 50 $\mathrm{mmHg}$ systolic was present at the end of operation in 3 patients (Cases 4,5 , and 7) and represented in each case a rise towards the level obtaining before the banding procedure. The severity of the pulmonary vascular resistance (PVR) before the banding operation, ranging from 4 to 22 PVR units per square metre body surface area (BSA), did not provide a satisfactory guide to the pulmonary artery blood pressure to be expected after banding or after reconstruction of the main pulmonary artery. For example, the patient with the most severe residual hypertension (Case 4) had had a much lower pulmonary vascular resistance value than another (Case II) who showed a satisfactory fall in the right ventricular and pulmonary artery pressure after the repair operation.

As intended the banding operation procured reduction in the main pulmonary artery pressure and a decrease in the size of

TABLE Haemodynamic findings in I5 patients

\begin{tabular}{|c|c|c|c|c|c|c|c|c|c|c|c|c|}
\hline \multirow[t]{2}{*}{$\begin{array}{l}\text { Case } \\
\text { No. }\end{array}$} & \multirow{2}{*}{$\begin{array}{l}\text { Age } \\
\text { when } \\
\text { main } \\
\text { pulm. } \\
\text { artery } \\
\text { banded } \\
\text { (mth) }\end{array}$} & \multirow{2}{*}{$\begin{array}{l}\text { Age } \\
\text { at } \\
\text { 2nd } \\
o p . \\
(y r)\end{array}$} & \multirow{2}{*}{$\begin{array}{l}\text { Main pulm. } \\
\text { artery systolic } \\
\text { pressure before } \\
\text { banding (mmHg) }\end{array}$} & \multicolumn{2}{|c|}{$\begin{array}{l}\text { Systolic pressure } \\
\text { after banding } \\
(\mathrm{mmHg})\end{array}$} & \multicolumn{2}{|c|}{$\begin{array}{l}\text { Systolic pressure } \\
\text { after 2nd op. } \\
(\mathrm{mmHg})\end{array}$} & \multirow[t]{2}{*}{$\begin{array}{l}Q_{p} / Q_{s} \\
\text { before } \\
\text { banding }\end{array}$} & \multirow[t]{2}{*}{$\begin{array}{l}Q p / Q s \\
\text { after } \\
\text { banding }\end{array}$} & \multirow{2}{*}{$\begin{array}{l}\text { Diameter } \\
\text { of ventric. } \\
\text { septal } \\
\text { defect at } \\
\text { op. }(\mathrm{mm})\end{array}$} & \multirow[t]{2}{*}{$\begin{array}{l}P V R \\
\text { units } / m^{2} \\
B S A\end{array}$} & \multirow[t]{2}{*}{ Result } \\
\hline & & & & $\begin{array}{l}\text { Right } \\
\text { ventricle }\end{array}$ & $\begin{array}{l}\text { Main } \\
\text { pulm. } \\
\text { artery }\end{array}$ & $\begin{array}{l}\text { Right } \\
\text { ventricle }\end{array}$ & $\begin{array}{l}\text { Main } \\
\text { pulm. } \\
\text { artery }\end{array}$ & & & & & \\
\hline $\mathbf{I}$ & 16 & 4 & 60 & IIO & 88 & 42 & 42 & $I \cdot 5: I$ & $I \cdot 5: I$ & Io & II & $A \& W$ \\
\hline 2 & 18 & 4.5 & 90 & II 8 & 50 & 60 & 30 & $2 \cdot 0: 1$ & $1 \cdot 3: 1$ & 10 & 13 & A \& W \\
\hline 3 & $3 I$ & 6 & 120 & 145 & 70 & - & - & $2 \cdot 0: 1$ & $1 \cdot 3: 1$ & 20 & 22 & Died \\
\hline 4 & 100 & $11 \cdot 5$ & 100 & 128 & 60 & 72 & 70 & $I \cdot 4: I$ & $I \cdot 7: 1$ & 20 & 9.5 & $A \& W$ \\
\hline 5 & 8 & 5 & 50 & IIO & 28 & 55 & 53 & $2 \cdot 7: 1$ & $0.76: 1$ & 15 & 17 & $A \& W$ \\
\hline 6 & 4 & 5 & 60 & 49 & 15 & 45 & 40 & $I \cdot 4: I$ & I:I & 0 & 22 & $A \& W$ \\
\hline 7 & 4 & 5 & 60 & 99 & 18 & 70 & 60 & $3 \cdot 0: 1$ & $0.81: 1$ & 15 & 9 & $A \& W$ \\
\hline 8 & 6 & 5 & 50 & 125 & 20 & 45 & 40 & $2 \cdot 5: 1$ & $2 \cdot 0: 1$ & 20 & 9.5 & Died \\
\hline 9 & 7 & 4 & 50 & 84 & 37 & - & - & $2 \cdot 8: 1$ & I.25: I & 15 & 4 & $A \& W$ \\
\hline 10 & Io & $4 \cdot 5$ & 65 & 89 & 29 & - & - & $2 \cdot 5: 1$ & $2 \cdot 0: 1$ & I0 & 9.5 & $A \& W$ \\
\hline II & 12 & $4 \cdot 5$ & 80 & 85 & 52 & 35 & 30 & $3 \cdot 8: 1$ & $1 \cdot 3: 1$ & 30 & 15.5 & Died \\
\hline 12 & 20 & 5 & 60 & 60 & 37 & 10 & 2 & $3 \cdot 6: 1$ & $I \cdot 4: 1$ & 5 & 13 & $A \& W$ \\
\hline 13 & 4 & 4 & 40 & 105 & 26 & 45 & 30 & $3 \cdot 0: 1$ & $0.5: 1$ & 30 & 6 & Died \\
\hline 14 & 4 & 5 & 65 & 105 & 42 & 45 & 40 & $2 \cdot 4: I$ & $x \cdot 3: x$ & 15 & 15.5 & $A \& W$ \\
\hline 15 & 12 & 4 & 50 & 95 & 40 & 70 & 45 & $2 \cdot 6: 1$ & $I \cdot 3: I$ & 20 & I0 & $A \& W$ \\
\hline
\end{tabular}


the arteriovenous shunt, but in 3 cases to the extent of causing shunt reversal. In one instance (Case 6) the ventricular septal defect had closed spontaneously before the second operation, at which nothing more than the reconstruction of the main pulmonary artery was required. In one instance the residual defect was small (less than Io $\mathrm{mm}$ ), while in 13 it remained of substantial size (ro to $30 \mathrm{~mm}$ ), being $30 \mathrm{~mm}$ in diameter in 2 .

Of the 2 older children subjected to pulmonary artery banding, I died at the age of 6 years during the second operation because of complete heart block, whereas the other had a successful repair operation at the age of $I I_{\frac{1}{2}}$ years.

\section{Discussion}

Our policy since 1964 has been to recommend palliative banding of the main pulmonary artery in children in the first year of life whenever congestive cardiac failure incompletely relieved by digoxin therapy has been caused by ventricular septal defects complicated by pulmonary hypertension (Reid $e t$ al., 1968). We have moreover been reluctant because of the risk involved (Coleman et al., 1968) to recommend, even in the second and third years of life, radical surgery for ventricular septal defects which at that age are causing cardiomegaly, pulmonary hypertension, and failure to thrive. For this reason, 4 patients between I year and 3 years were also subjected to pulmonary artery banding.

The 8-year-old who was accorded the same form of treatment had begun to develop pulmonary vascular obstructive disease and was thought therefore to be an unsuitable subject for an immediate repair operation on his septal defect. This was the only instance in which pulmonary blood flow increased after the banding operation. It is tempting to speculate that this happened either because pulmonary arterial obstructive disease had resolved in response to a reduction in flow pressure from 100 to $60 \mathrm{mmHg}$ for a period of 3 years, or because this pressure drop interrupted the activity of a humoral mechanism responsible for the maintenance of increased arteriolar tone.

The policy which we have adopted in relation to the majority of our patients has been in keeping with the practice elsewhere (Dammann et al., 196I; Craig and Sirak, 1963; Friedberg, 1966; Hallman et al., 1966; Stark et al., 1969), but comparatively little has been reported on the subject of the subsequent repair of the septal defect and pulmonary trunk. Dammann et al. (196I) recorded 7 survivors from II patients subjected to this second operation, Hallman et al. (1966) 13 survivors from 14, and Stark et al. (I969) I 5 survivors from 21.2 of the 4 deaths among our patients were unexpected (Cases 8 and 13), with no suggestion that the situation had been influenced by persisting pulmonary arterial changes (Io and 6 PVR units $/ \mathrm{m}^{2}$ BSA before banding). The other 2 deaths (Cases 3 and $\mathrm{II}$ ) were in children whose pulmonary vascular resistance before banding had been at a higher level ( 22 and I5 units $/ \mathrm{m}^{2} \mathrm{BSA}$ ). In retrospect the banding procedure in the first had met with little success inasmuch as the main pulmonary artery systolic pressure fell from $120 \mathrm{mmHg}$ to remain at $70 \mathrm{mmHg}$. This experience, together with the eventual fatal outcome, seems to accord well with the advanced histological changes found in the small pulmonary arteries. In the other, the main pulmonary artery pressure, though reduced, did not return to the normal range after banding, but the death from congestive cardiac failure several weeks after an apparently successful second operation could not be confidently attributed to this.

The range of pulmonary vascular resistance values (4 to 22 PVR units $/ \mathrm{m}^{2} \mathrm{BSA}$ ) before pulmonary artery banding disclosed some very high figures, but there was in fact no reliable association between these and the final result on which to base a prognostic index. One patient (Case 13) who died had a value of 6 before the first operation whereas a survivor (Case 6) had the same high value of 22 PVR units as another who died (Case 3) and whose small pulmonary arteries had shown substantial structural changes in the medial coat. Moreover the other patient (Case 4) known to have changes in the walls of the small pulmonary arteries had a much lower PVR value (9.5 units $/ \mathrm{m}^{2} \mathrm{BSA}$ ), made a good response to pulmonary artery banding, and successfully survived his second operation. Further uncertainty concerning the prognostic significance of pulmonary vascular resistance values arises from the fact that in 2 instances in which it was high (Cases 6 and 12) substantial spontaneous closure of the defect took place after pulmonary artery banding, resulting in its disappearance in one. The 3 patients (Cases 4, 5, and 7) whose main pulmonary artery pressure rose again after the second operation showed no untoward effects and, with the interruption of the shunt, seemed likely to us to experience a spontaneous fall in the main pulmonary artery pressure.

The two most important factors in precipi- 
tating congestive cardiac failure in infants with ventricular septal defect seem to be the volume of pulmonary blood flow and the magnitude of pulmonary vascular disease. In reality these factors are mutually exclusive. The greater the pulmonary blood flow is, the less must be the pulmonary vascular resistance; the more severe the pulmonary vascular resistance the smaller will be the pulmonary blood flow. Dammann et al. (196I) have however demonstrated, by means of haemodynamic studies and lung biopsies, that pulmonary artery banding will cause both a fall in pulmonary blood flow and an improvement in pulmonary vascular pathology. Hallman et al. (1966) have pointed to the dramatic reduction in the pulmonary blood flow which pulmonary artery banding may produce from, in their experience, an average pulmonary: systemic blood flow ratio $(\mathrm{Qp} / \mathrm{Qs})$ of $6 \cdot 3$ :I dropping to $I \cdot 5: I$ after operation. We have not experienced such dramatic changes, our average $\mathrm{Qp} / \mathrm{Qs}$ before pulmonary artery banding being $2.46: 1$ and afterwards at the subsequent cardiac catheterization I.29: $I$; this nevertheless represents a mean reduction in the shunt blood flow (relative to systemic flow) to I9 per cent of the level before operation. It is certain however that the reduction in shunt volume is at least partly caused by a measure of spontaneous narrowing of the septal defect.

The previous experience of the Royal Hospital for Sick Children had been that 40 per cent of infants admitted because of serious symptoms attributable to ventricular septal defects with pulmonary hypertension, and not operated upon, died during the first year of life (Coleman, I965). Furthermore the repair of ventricular septal defects in children who had survived the first year of life had a I4 per cent mortality (Coleman et al., I968). An approximation, derived from these figures, of the mortality rate of seriously ill children treated in the first year of life with medical measures only, and later subjected to a repair operation, can be deduced to be 48 per cent. A survey of experience with pulmonary artery banding, applied to infants suffering from the same defect complicated by pulmonary hypertension and congestive cardiac failure (Reid et al., 1968), revealed I death in 21 patients ( $4 \%$ mortality). The mortality rate derived from the present series (excluding patients older than I year when banding was performed) was 3 in 10, or 30 per cent. The approximate overall mortality for this active approach, through two operative procedures, to those acutely ill in the first year of life appears, therefore, on the data available, to be
32 per cent. Though there remains this considerable mortality rate, the more recent survival rate of 68 per cent represents a substantial improvement on the 52 per cent survival rate which existed before pulmonary artery banding was introduced.

The question of the indications for pulmonary artery banding remains to be considered and there is no clear answer. Mounting experience of infants with ventricular septal defects, pulmonary hypertension, and congestive cardiac failure leads to a recognition that many more than was once realized show gradual improvement, probably reflecting spontaneous narrowing of the defect. Since pulmonary artery banding and the subsequent repair operation are not without hazard a selection procedure is mandatory. The minority whose cardiac catheterization reveals pulmonary hypertension with little increase in pulmonary blood flow must claim attention as in need of the banding procedure. Those however whose pulmonary hypertension reflects excessive blood flow rather than high resistance are probably in need of further close supervision rather than of immediate operation. Persistent failure to thrive, persisting breathlessness, recurrent lower respiratory tract infections, or dependence upon drug therapy other than digoxin in a standard maintenance dose would be accepted by us as indications for pulmonary artery banding even in the high-flow group.

It is clear from the results obtained that the treatment for this condition is still far from ideal, and consideration must continue to be given to the possibility of substituting primary repair of ventricular septal defects in the first year of life for the two-stage procedure which we have adopted. In this respect the excellent results of Kirklin and his colleagues in children over the age of 6 months are encouraging (Cartmill et al., 1966) as are modifications in the technique of profound hypothermia for open heart surgery in the very young, which are now taking place (Barratt-Boyes et al., 1970). The first 6 months of life appear still to be the most uncertain and challenging period as regards surgical therapy. Only longer and wider experience will determine whether lower mortality rates can be consistently achieved by these methods in other centres.

We are indebted to Mr. T. M. Welsh, Mr. N. McSwan, Mr. J. F. R. Bentley, Dr. J. A. Inall, and Dr. W. B. Doig who collaborated with us in the care of these patients, and to Dr. S. P. Rawson and Dr. Elizabeth M. Sweet for radio-diagnostic advice. We are grateful to the departments of pathology of the Royal Hospital for Sick Children 
and of the Victoria Infirmary, Glasgow, for assistance, and to the physicians who referred patients.

\section{References}

Barratt-Boyes, B. G., Simpson, M., Seelye, E., and Neutze, J. (1970). Intracardiac surgery in neonates and infants using profound hypothermia (Kyoto technique). In VI World Congress of Cardiology, 1970. Cardiovascular Research, 71.

Cartmill, T. B., DuShane, J. W., McGoon, D. C., and Kirklin, J. W. (1966). Results of repair of ventricular septal defect. Fournal of Thoracic and Cardiovascular Surgery, 52, 486.

Coleman, E. N. (I965). Serious congenital heart disease in infancy. British Heart fournul, $27,42$.

Coleman, E. N., Reid, J. M., Inall, J. A., and Stevenson, J. G. (1968). Ventricular septal defect repair in childhood. British Heart fournal, 30, 845.

Craig, T. V., and Sirak, H. D. (I963). Pulmonary artery banding. An analysis of 38 cases. Fournal of Thoracic and Cardiovascular Surgery, 45, 599.

Dammann, J. F., McEachen, J. A., Thompson, W. M., Smith, R., and Muller, W. H., Jr. (I96I). The regression of pulmonary vascular disease after the creation of pulmonary stenosis. Fournal of Thoracic and Cardiovascular Surgery, 42, 722.
Friedberg, C. K. (1966). Diseases of the Heart, 3rd ed., p. 125. W. B. Saunders, Philadelphia and London.

Hallman, G. L., Cooley, D. A., and Bloodwell, R. D. (1966). Two-stage surgical treatment of ventricular septal defect: results of pulmonary artery banding in infants and subsequent open-heart repair. Fournal of Thoracic and Cardiovascular Surgery, 52, 476.

Oschner, J. L., Cooley, D. A., McNamara, D. G., and Kline, A. (I962). Surgical treatment of cardiovascular anomalies in 300 infants younger than one year of age. Fournal of Thoracic and Cardiovascular Surgery, 43, 182.

Reid, J. M., Barclay, R. S., Coleman, E. N., Stevenson, J. G., Welsh, T. M., and McSwan, N. (1968). Pulmonary artery banding in congenital heart disease associated with pulmonary hypertension. Thorax, 23, 385.

Stark, J., Aberdeen, E., Waterston, D. J., BonhamCarter, R. E., and Tynan, M. (1969). Pulmonary artery constriction (banding): a report of 146 cases. Surgery, 65, 808.

Requests for reprints to Dr. Eric N. Coleman, Department of Cardiology, Royal Hospital for Sick Children, Glasgow G3 8SJ. 